\title{
Gene mutations of acute myeloid leukemia in the genome era
}

\author{
Tomoki Naoe $\cdot$ Hitoshi Kiyoi
}

Received: 17 October 2012/Revised: 9 January 2013/Accepted: 15 January 2013/Published online: 29 January 2013

(C) The Japanese Society of Hematology 2013

\begin{abstract}
Ten years ago, gene mutations found in acute myeloid leukemia (AML) were conceptually grouped into class I mutation, which causes constitutive activation of intracellular signals that contribute to the growth and survival, and class II mutation, which blocks differentiation and/or enhance self-renewal by altered transcription factors. A cooperative model between two classes of mutations has been suggested by murine experiments and partly supported by epidemiological findings. In the last 5 years, comprehensive genomic analysis proceeded to find new gene mutations, which are found in the epigenome-associated enzymes and the molecules never noticed so far. These new mutations apparently increase the complexity and heterogeneity of AML. Although a long list of gene mutations might have been compiled, the entire picture of molecular pathogenesis in AML remains to be elucidated because gene rearrangement, gene copy number, DNA methylation and expression profiles are not fully studied in conjunction with gene mutations. Comprehensive genome research will deepen the understanding of AML to promote the development of new classification and treatment. This review focuses on gene mutations that were recently discovered by genome sequencing.
\end{abstract}

Keywords Acute myeloid leukemia - Chromosome translocation - Gene mutation - Genome sequencing . Epigenetics · Prognosis

T. Naoe $(\bowtie) \cdot$ H. Kiyoi

Department of Hematology and Oncology, Nagoya University

Graduate School of Medicine, Nagoya, Japan

e-mail: tnaoe@med.nagoya-u.ac.jp

\section{Introduction}

Acute myeloid leukemia (AML) is a neoplasm of the clonal and irreversible expansion of myeloid blasts and most common among adult acute leukemia. It is heterogeneous regarding clinical feature, morphological and immunophenotypic features, and karyotypic and genetic abnormalities [1, 2]. Initial molecular biological studies started with cloning recurrent chromosomal translocations; RUNX1-RNNX1T1, CBFB-MYH11, PML-RARA, and MLL gene rearrangement from $\mathrm{t}(8 ; 21), \operatorname{inv}(16), \mathrm{t}(15 ; 17)$ and $11 \mathrm{q} 23$ translocations, respectively. These studies presented a paradigm of leukemogenesis. The translocations generate chimeric transcriptional factors, which alter expressions of genes critical for hematopoietic development and/or differentiation. In vitro and in vivo experiments support that these abnormalities block hematopoietic differentiation and/or promote self-renewal, while their transgenic mice developed AML with low frequency except MLL-AF4 and $M L L-A F 9$ [3-7]. In addition, critical transcriptional factors for myeloid differentiation, CEBPA and RUNX1, are pointmutated in AML without above translocations [8-10]. Importantly, this class of mutations is closely associated with morphology, phenotypes and prognosis of AML and is mutually exclusive [11].

On the other hand, classical transformation assay revealed NRAS or KRAS mutation in AML as well as solid tumors $[12,13]$. Thereafter, the receptor tyrosine kinaseencoding genes, FLT3 and KIT, were found to be frequently mutated in AML [14-20]. A receptor tyrosine kinase (RTK)-RAS-MAPK pathway is one of the most important intracellular signaling in myeloid malignancies including myeloproliferative neoplasm (MPN) and myelodysplastic syndrome (MDS). In vitro and in vivo studies suggest that this class of mutations augments proliferation and survival 
signals, but does not induce AML but MPN by itself in murine model [21]. Clinically, this type of mutations sometimes emerge or occasionally disappear during clinical course of AML and MDS [22-24]. These mutations (so-called class I mutation) are mutually exclusive but not so strictly as the above class of mutations (class II mutation), and not related with AML subtypes except for the preference of KIT mutation to CBF leukemia.

Simultaneous expression of two classes of mutations, i.e. PML-RARA and FLT3-ITD, in murine hematopoietic progenitor cells caused AML with high frequency and the following similar experiments suggested that two classes of mutations work synergistically to develop AML in vivo [6]. The cooperating model does not only fit with the murine experiments, but also with epidemiological findings in human AML, providing the backbone for the WHO classification in AML [25]. This model is also used to characterize the new gene mutation. NPM1 mutation which was found in 2005 and the functional significance not elucidated at that time are exclusive to class II mutations and frequently overlaps with class I mutations, suggesting that it belongs to class II mutation [26, 27]. However, it is often difficult to dissect functions of class I and class II mutations [7]. For example, a representative gene mutation of class I, FLT3-ITD, does not only mediate proliferation and anti-apoptosis signals, but also block differentiation through down-regulating C/EBP $\alpha$ and PU.1 [28-30].

Year 2009 is the first year of leukemia genome. TET2 located on $4 \mathrm{q} 24$ was identified as a target of deletions or mutations in myeloid malignancies [31, 32]. IDHI/2 mutation was found by whole-genome sequencing of a primary, cytogenetically normal AML (CN-AML) [33]. In the next year, DNMT3A and EZH2 were recognized to be mutated by genome-based methods [34, 35]. Either of these new mutations directly targets epigenetic control such as DNA/histone methylation status [36]. In addition to them, mutations were found in transcriptional corepressors, ASXL1, BCOR and BCORL1 [37-39]. In 2012, cohesion complex-encoding gene mutation was reported [40]. Most these mutations were generally identified in all types of myeloid malignancies, while discovery of frequent mutations of splicing machinery, which is highly associated with myelodysplasia and the formation of ring sideroblasts, is important to clarify disease type- and/or phenotypespecific pathological roles of gene mutations [41, 42].

Although more years are needed to draw the whole picture of AML gene abnormalities, we may have obtained a list of recurrently mutated genes in AML (Table 1). Although all the mutations are likely to be unrelated at first glance, if looking at its features, they are found to be related each other. In Fig. 1, we propose a pathway map, in which mutated gene products in AML are functionally connected. In this figure, we make a point not to draw uncontrolled cell-cycle and cell survival which are secondary operations from mutated gene products. In the case of acute lymphoblastic leukemia and lymphoma, genes associated with cell-cycle and cell survival are frequently targeted, suggesting that the mutational profiles depend on its cellular context. Accordingly, it may be possible to highlight that AML is a disease of transcription, in another word, differentiation.

Next, we summarize gene mutations found in AML during these 5 years.

\section{Mutations in epigenetic modifiers}

\section{TET2}

The TET family proteins (Tet1, Tet2, Tet3) are catalyzing enzymes 5-methylcytosine (5-mC) to hydroxymethylcytosine (5-hmC), which have been shown as an initial process of DNA demethylation [43-45]. Mutations of the TET2 gene have been found in various myeloid malignancies; 8-27\% of AML, 20-25\% of MDS, 4-13\% of MPN [31, 32, 46-49]. TET2 mutations are loss-of-function of mono allele in most cases, including missense, frameshift and nonsense mutations. Importantly, TET2 mutations are almost mutually exclusive with $I D H 1 / 2$ mutations, suggesting a similar epigenetic defect as IDHI/2 mutations $[36,50]$.

The base $5-\mathrm{hmC}$ is recently suspected as a new epigenetic marker in addition to being an intermediate metabolite during cytosine demethylation. It has been suggested that 5-hmC is associated with transcriptional regulation for promoter and enhancer functions [51-53]. In vivo, TET2 inactivation induced in hematopoietic abnormalities predisposing not only myeloid but also lymphoid malignancies [54]. However, the precise mechanisms and downstream effects of TET2 are yet unknown.

The prognostic relevance of TET2 mutations remains controversial. Some studies suggest an adverse impact of TET2 mutations on outcome in certain AML subgroups; in other studies, no prognostic significance was found [47-50].

\section{DNMT3A}

DNA methyltransferase (DNMT) family enzymes transfer a methyl radical to DNA, and in human, DNMT3A and 3B are methyltransferases that convert cytosine to 5-methylcytosine and generate de novo DNA methylation, whereas DNMT1 mediates maintenance methylation [55].

Mutations of DNMT3A are reported in $18-23 \%$ of AML, including 20-35\% with normal karyotype, $8 \%$ of MDS and 7-15\% of MPN [34, 36, 50, 56-58]. The locus 
Table 1 Recurrently mutated genes in AML

\begin{tabular}{|c|c|c|c|}
\hline Function & Gene & Mutation frequency & Grouping \\
\hline \multirow[t]{4}{*}{ Tyrosine kinase } & FLT3 & $\begin{array}{l}\text { ITD: } 20-28 \% \\
\text { KDM: } 5-10 \%\end{array}$ & \multirow[t]{8}{*}{ Class I } \\
\hline & KIT & $25-30 \%$ in CBF-AML & \\
\hline & JAK1 & $1-3 \%$ & \\
\hline & JAK3 & $1-2 \%$ & \\
\hline \multirow[t]{2}{*}{ RAS pathway } & NRAS & $9-14 \%$ & \\
\hline & KRAS & $5-17 \%$ & \\
\hline Protein phosphatase & PTPN11 & $4-5 \%$ & \\
\hline Ubiquitin pathway & CBL & $2-3 \%$ & \\
\hline Nuclear-cytoplasmic shuttling phosphoprotein & NPM1 & $25-35 \%$ & \multirow[t]{9}{*}{ Class II } \\
\hline \multirow[t]{8}{*}{ Transcription factor } & CEBPA & $10-20 \%$ & \\
\hline & RUNX1 & $5-13 \%$ & \\
\hline & GATA2 & $3-5 \%$ & \\
\hline & RUNX1-RUNX1T1 & $10-15 \%$ & \\
\hline & CBFB-MYH11 & $3-8 \%$ & \\
\hline & PML-RARA & $5-10 \%$ & \\
\hline & MLL fusion & $5-9 \%$ & \\
\hline & DEK-NUP214 & $1 \%$ & \\
\hline \multirow[t]{3}{*}{ DNA hydroxymethylation } & TET2 & $8-27 \%$ & \multirow{7}{*}{$\begin{array}{l}\text { Class III? (mutations in } \\
\text { epigenetic modifires) }\end{array}$} \\
\hline & IDH1 & $6-9 \%$ & \\
\hline & $\mathrm{IDH} 2$ & $9-12 \%$ & \\
\hline DNA methylation & DNMT3A & $18-23 \%$ & \\
\hline Histone 3 K27 methylation & $\mathrm{EZH} 2$ & Rare in AML $8-12 \%$ of MPN-BC & \\
\hline \multirow[t]{2}{*}{ Histone $3 \mathrm{~K} 4$ methylation } & \multirow[t]{2}{*}{ MLL } & $5-6 \%$ & \\
\hline & & PTD: $5-13 \%$ & \\
\hline Histone 3 K27 tri-methylation & ASXL1 & $3-11 \%$ & \\
\hline \multirow[t]{2}{*}{ Transcriptional corepressor } & $\mathrm{BCOR}$ & $4-5 \%$ & \multirow[t]{8}{*}{$?$} \\
\hline & BCORL1 & $6 \%$ & \\
\hline \multirow[t]{4}{*}{ Cohesin complex } & STAG2 & $2 \%$ & \\
\hline & SMC3 & $3 \%$ & \\
\hline & SMC1A & $3 \%$ & \\
\hline & RAD21 & $2 \%$ & \\
\hline \multirow[t]{2}{*}{ Tumor suppressor } & TP53 & $7-12 \%$ & \\
\hline & WT1 & $10-13 \%$ & \\
\hline
\end{tabular}

of the mutations is clustered at R882 in a half of cases and distributed widely in other cases. The mutations are supposed to be loss-of-function, although it is not well characterized. Aberrant methylation patterns induced by the mutation might be associated with initiation and progression of leukemia, although the biological consequences of the mutations remain unclear [55-57, 59]. In vivo study revealed that Dnmt3a-null hematopoietic stem cells had an increased self-renewal capacity and lost their differentiation potential, which was accompanied by aberrant methylation pattern implicated in leukemogenesis [60, 61]. However, knockout of Dnmt3a alone was not sufficient to initiate leukemia.

DNMT3A mutations might be associated with poorer prognosis, and is frequently associated with NPM1 and FLT3 mutations [34, 50, 56-58]. Several different loss-offunction mutations have been found in all exons of DNMT3A, while a missense point mutation at amino acid R882 which decreases catalytic activity and DNA binding affinity is most frequently identified. 


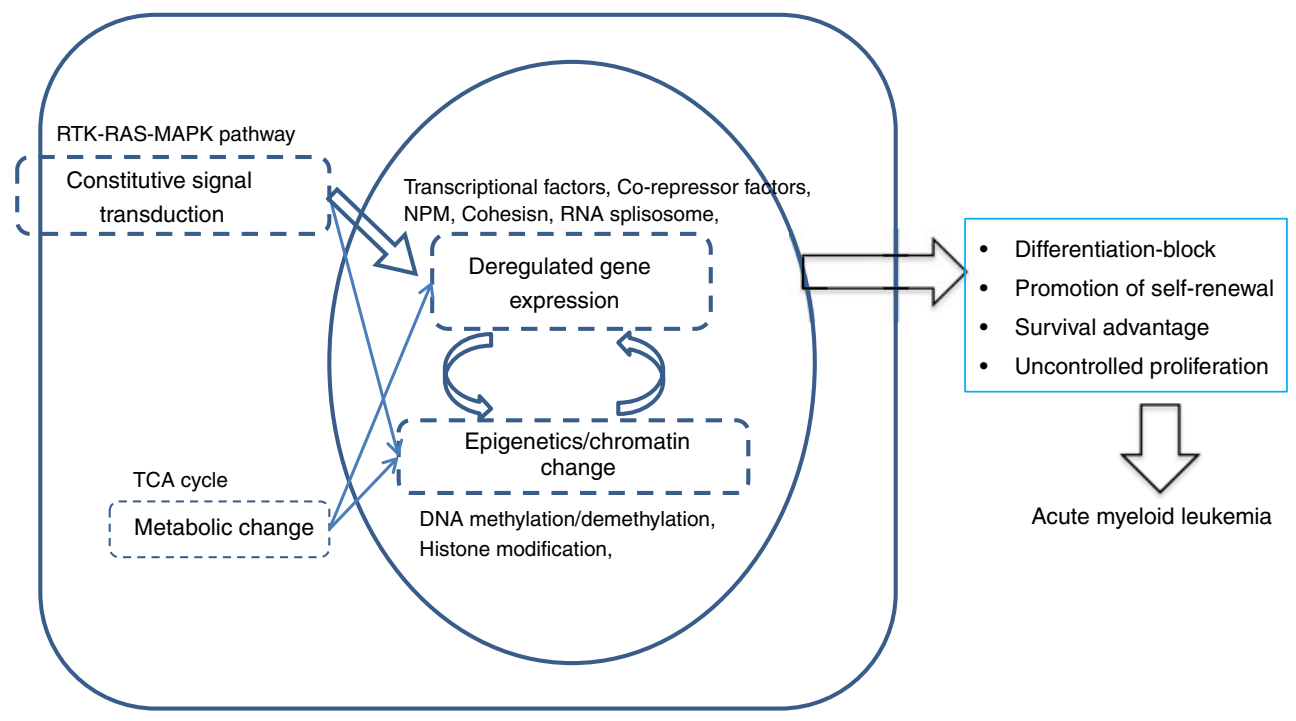

Fig. 1 A schematic diagram of intracellular signaling associated with AML. Gene mutations in AML are functionally classified into three general classes: constitutive signal transduction (class I), deregulated gene expression (class II), and epigenetics/chromatin change (class III). Three classes of mutations are functionally linked in this model,

\section{EZH2}

$\mathrm{EZH} 2$ is a $\mathrm{H} 3 \mathrm{~K} 27$ methylatransferase which is one of the components of polycomb repressive complex 2 (PRC2) [62]. PRC2 has been supposed to be required for silencing target genes and maintaining "stemness" in stem cells [63]. Several studies established that EZH2 is overexpressed in solid tumors, and high expression is associated with tumor progression, indicating the role of EZH2 as an oncogene in these tumors [64]. Mutation at the tyrosine 641 residue within the catalytic domain of EZH2 is recurrently identified in germinal center-type diffuse large B-cell lymphoma and follicular lymphoma [65]. Biochemical analysis revealed that Y641 mutation increases di- and tri-methylation of H3K27 in spite of impairing H3K27 mono-methylation. Furthermore, in vivo study suggested that EZH2 augments leukemogenesis by reinforcing differentiation block in AML [66]. These results are consistent with the assumption that the increasing H3K27 methylation activity of PRC2 represses the expression of tumor suppressor genes. In contrast to these data, a wide variety of loss-of function mutation of the $E Z H 2$ gene has been found in myeloid malignancies. It is found in $6 \%$ of MDS and 3-13\% of MPN, but extremely rare in AML [35, 36, 67]. Among them, mutations are prevalent in CMML and associated with adverse outcome [68]. The function of EZH2 remains unclear in hematopoiesis, because Ezh2 conditional knock-out (KO) mice had minimal myeloid differentiation defects [69]. However, loss-of-function rather than overexpression of EZH2 might be involved in whereas according to the Gilliland's model two classes of mutation work in a cooperative or complementary manner [26]. The molecular alterations are eventually summarized toward the deregulated gene expression in molecular pathogenesis

pathogenesis of myeloid malignancies through the insufficient H3K27 methylation status.

\section{$I D H 1 / 2$}

IDH1 and IDH2 are NADP-dependent isocitrate dehydrogenases that catalyze isocitrate to $\alpha-\mathrm{KG}$ in TCA cycle, and the subcellular localizations are in cytosol and mitochondria, respectively [70]. IDHI/2 mutations are detected in 15-33\% of AML mostly in normal karyotype-AML, $3.5 \%$ of MDS, $2-5 \%$ of MPN, and also in glioma and multiple endochondromatosis [70-74]. The mutations have been shown to exhibit a gain-of-function leading to aberrant accumulation of 2-hydroxyglutarate (2-HG). 2-HG is an oncometabolite which inhibits an enzymatic activity of TET2 and stimulates HIF1- $\alpha$, leading to initiation and promotion of cancer [75-77]. Therefore, the IDHI/2 mutations functionally overlap with TET2 mutation, resulting in hypermethylation of leukemia cells, disrupt TET2 function, and impair hematopoietic differentiation. Recently, IDH mutation was reported to expand murine hematopoietic progenitor pool as well as altering epigenetics [76].

The impact of $I D H$ mutations on survival of AML patients is unclear like the mutation of TET2. Some studies have observed no difference in outcome with respect to the $I D H$ mutation status, while others have demonstrated a poor prognostic impact in certain AML subgroups. Recent studies suggest that the impact of $I D H 2$ mutation on prognosis depends on the mutation site, with the IDH2 R140 mutation being an independent favorable prognostic factor in AML patients [71]. 


\section{Cohesin complex genes}

Cohesin complex regulates the cohesion and separation of sister chromatids during cell division, and recently has been known to regulate gene transcription associated with cell development and differentiation [78, 79]. Cohesion complex is composed by Smc1, Smc3, Rad21 and SA1/2. SA2-encoding gene, STAG2, and RAD21 are reported to be deleted in AML genome, and recently SMC1A, SMC3, STAG2 and RAD21 are found to be mutated in a loss-offunction manner [40, 80, 81]. The mutations are found in a variety of AML except acute promyelocytic leukemia and are unrelated to chromosomal instability. The clinical and biological significance of cohesion complex-coding genes is to be further elucidated.

\section{Transcriptional corepressor}

\section{$B C O R$}

BCOR protein was identified as an interacting corepressor of BCL6, a POZ/zinc finger transcription repressor that is required for germinal center formation and may influence apoptosis [82]. Mutations in the BCOR gene have also been found to be associated with AML [38].

\section{ASXL1}

ASXL1 is involved in the maintenance of both activation and silencing of the HOX genes, which are involved in development of body axial structure as well as in chromatin remodeling [83]. ASXL1 also acts as a corepressor of nuclear receptors such as PPAR $\gamma$ and RAR $\gamma$ [84]. Although the KO mice of ASXL1 have no defect in hematopoiesis [83], it has been recently reported that ASXL1 mutants promote myeloid transformation through loss of PRC2mediated H3K27 tri-methylation [85]. ASXL1 mutations have been found in 3-11\% of AML, $14 \%$ of MDS and $2-23 \%$ of MPN. The mutation frequency is high, from 27 to $49 \%$ in MDS/MPN including CMML [50, 86-88]. The mutations consist of missense, nonsense and frame shift, suggesting a loss-of-function. It has been also reported that ASXL1 mutation status can change during disease evolution.

\section{Interaction of genetic alterations in AML}

Several somatic mutations are accumulated in cancer cells during the development and progression. These mutations are classified into two types of mutations: "driver" mutations that provide a selective advantage and "passenger" mutations that are simply happened without any role.
In AML, it has been demonstrated both by clinical analysis and experimental models that the accumulation of two types of driver mutations (class I and class II mutations) is required for the clonal expansion of leukemia cells [7]. Therefore, it is important to evaluate whether each mutation is driver or passenger mutation and which combinations of overlap mutations are associated with the leukemogenesis and clinical significance in AML. To date, several combinations of class I and class II mutations have been apparent. Although FLT3-ITD and PML-RARA, KIT mutation and RUNX1-RUNX1T1 or CBFB-MYH11, and FLT3-ITD and NPM1 mutation are frequently identified, the other combinations are relatively infrequent. Recently, it has been suggested that a part of mutations, such as epigenetic modifiers, generates a new class (class III), because of their overlap mutations both with class I and class II mutations (Fig. 2) [36, 50].

Consistent with the biological evidence that TET2 and $I D H 1 / 2$ mutations are functionally overlapped, these mutations are mutually exclusive in AML cells [36]. Likewise, DNMT3A, ASXL1 and MLL mutations, which directly regulate methylation state of DNA and/or the histone, are exclusively identified in AML cells. Importantly, overlap mutation of TET2 or IDHI/2 mutation with DNMT3A, ASXL1 or MLL mutation is identified in AML cells. This overlap is infrequently identified, but indicates the possible involvement of more than one molecules, which show the opposite methylation status by these epigenetic mutations, in leukemogenesis. In addition, these epigenetic mutations might contribute to pathogenesis of AML in concert with class I and/or class II mutations because of their frequent overlap mutations. Particularly, TET2, IDHI/2 and DNMT3A mutations are frequently overlapped with FLT3 and NPM1 mutations. In contrast, ASXL1 and MLL mutations, which mainly affect the histone methylation status, are exclusively mutated with class I mutations, except for the frequent overlap of $M L L$-partial tandem duplication (MLL-PTD) and FLT3 mutations. Furthermore, ASXL1 and MLL mutations are overlapped both with class II, such as RUNXI and CEBPA, and TET2 or $I D H 1 / 2$ mutations $[37,87]$. On the other hand, ASXL1 mutation recurrently overlaps with $J A K 2, R A S$ and $N F 1$ mutations as well as $U 2 A F 35$ and RUNXI mutations in MDS and MPN [89, 90]. In addition, it has been demonstrated that knock down of ASXL1 collaborates with NRAS G12D mutation to promote myeloid transformation in vivo [85]. Since ASXL1 mutation is preferentially identified in secondary AML $(30.3 \%)$ rather than de novo AML (6.5\%), further analysis is required to clarify whether the oncogenic role of ASXL1 in de novo AML is the same as that of MDS and MPN [91].

More recently, mutations in cohesion complex genes (STAG2, SMC3, SMC1A and RAD21) have been discovered 
Fig. 2 Interaction of genetic alterations in AML frequently identified overlap mutations are shown. Mutations in epigenetic modifiers are overlapped both with class I and class II mutations

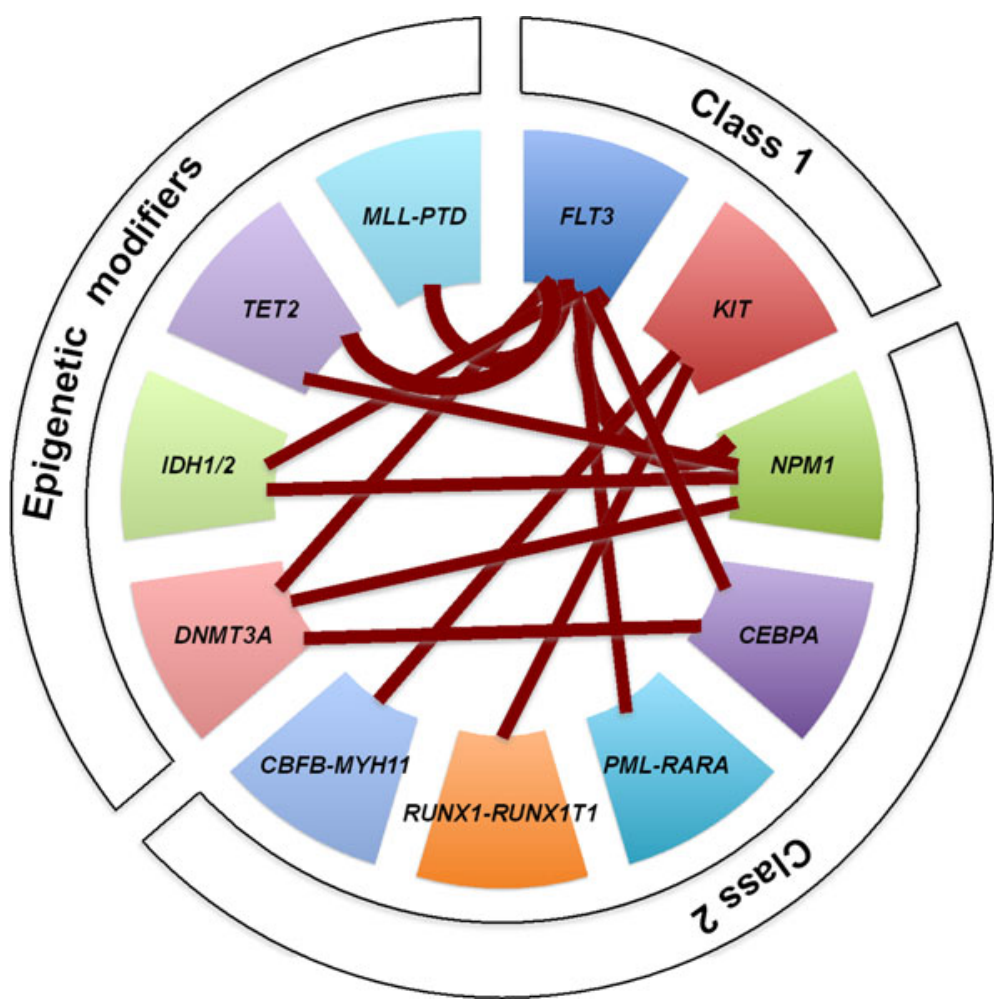

[40]. These mutations are reportedly mutually exclusive, indicating the redundant potential for leukemogenesis. Although mutations in cohesion complex genes were so far not identified in AML with PML-RARA, CBFB-MYH11 and $B C R-A B L 1$, their overlap mutations with class I, class II and epigenetic modifier mutations were identified. At present, it is unclear as to how these mutations are involved in the pathogenesis of AML, while their unique overlap pattern indicates the novel important pathway of leukemogenesis.

Several patterns of overlap mutations have been, to date, apparent as described above. However, the order of acquisition and stability of each mutation during the disease status is not fully elucidated. It has been well accepted that class II and epigenetic modifier mutations in stem/ progenitor cells, which confer an advantage in self-renewal of leukemia progenitors, are earlier events than class I mutation during the development of AML. However, the interaction of class II and epigenetic modifier mutations both at the initiation and progression stages of leukemia remains unclear. Comparable analyses of mutation status between the diagnosis and the relapse of AML revealed the loss of class II mutations, such as NPM1 and CEBPA mutations, at the relapse. In contrast, epigenetic modifier mutations are stably identified during the disease progression of AML, while they are frequently acquired at the later stage of MPN, suggesting their multiple oncogenic potency not only for the initiation, but also for progression in myeloid malignancies [22-24].

\section{Background mutation}

It is notable that several background mutations occur in normal hematopoietic cells [40]. Whole-genome analysis using normal hematopoietic cells revealed that the mutated gene number is lowest in the cord blood and increased according to the aging, irrespective of synonymous or nonsynonymous mutation. These results suggest that background mutations, which are randomly acquired in hematopoietic cells with age and stress, might be involved in the initiation of AML development. However, these results have raised further questions regarding how background mutations affect the acquisition of driver mutations and whether driver and background mutations cooperatively induce the clonal expansion. Furthermore, it is interesting that the number of background mutations is almost the same between AML with PML-RARA and normal karyotype, suggesting that most of the mutations found in AML are age-related background and leukemia-associated passenger mutations. In cytogenetically normal (CN)-AML, several kinds of driver mutations are involved in the initiation of AML, while those are not always stable during the progression of AML, and the number of background mutations is the same regardless the type of initiation driver mutations [22-24, 40, 92, 93]. These findings, therefore, suggest that pathological roles of back ground mutations might be different among the types of following driver mutations. 


\section{Prognostic relevance of genetic mutations in AML}

Although prognostic risk classification based on cytogenetics has been well accepted in AML, there is a clinical heterogeneity of the intermediate risk group, particularly CN-AML [94]. Recent advance and accumulation of prognostic relevance of recurrent genetic alterations have made possible more detailed risk stratification in AML patients.

The European LeukemiaNet (ELN) has recommended a novel risk classification system based on the cytogenetic and genetic status [95]. In this system, CN-AML is stratified into two risk groups according to the mutation status of FLT3, NPM1 and CEBPA: patients with NPM1 mutation but not FLT3-ITD and those with CEBPA mutation are included in the favorable risk (FR) group, and patients with FLT3-ITD and those without NPM1 mutation and FLT3ITD are categorized into intermediate-I risk group. Longterm prognosis according to the ELN classification system was retrospectively evaluated in two well-established cohorts, and both analyses demonstrated that the ELN system is useful for further risk stratification of younger adult patients with CN-AML. However, further studies are required to confirm prognostic relevance of epigenetic modifier mutations. In the patients who were treated on the Cancer and Leukemia Group B (CALGB) trials, TET2 mutation was identified to be a poor prognostic factor in the patients who were classified in the FR group of the ELN system [47]. In the patients who were treated on the Eastern Cooperative Oncology Group (ECOG) trials, only co-occurring NPMI and IDH1/2 mutations were identified to be the favorable factor for the long-term prognosis [50]. Although both analyses demonstrated possible prognostic implication of TET2 and IDH1/2 genes in the FR group, it was not evident in the patients registered to Munich Leukemia Laboratory in Germany [88]. Some groups reported adverse effect of DNMT3A, MLL and ASXL1 mutations on long-term prognosis in AML patients, their prognostic relevance is still controversial.

Table 2 shows prognostic relevance of relatively established genetic status in AML. However, therapeutic interventions based on the genetic status should be

Table 2 Prognostic relevance of mutation status

\begin{tabular}{ll}
\hline $\begin{array}{l}\text { Associated with good } \\
\text { prognosis }\end{array}$ & $\begin{array}{l}\text { Associated with } \\
\text { poor prognosis }\end{array}$ \\
\hline NPM1-Mt/FLT3-ITD negative & FLT3-ITD \\
CEBPA double mutation & TP53 mutation \\
NPM1-Mt (for achieving CR) & TET2 mutation \\
IDH2 mutation & ASXL1 mutation \\
& PHF6 mutation \\
\hline
\end{tabular}

carefully conducted, because no prospective study confirms the prognostic risk of each mutation. In the future, validation study and meta-analysis should be conducted.

\section{Conclusion}

Comprehensive genomic analyses using the next-generation sequencer have revealed a lot of mutations in AML. Although functional and prognostic implications of each mutation are not fully elucidated, novel cooperative effects of mutations are speculated. Particularly, it is important to clarify the interactions of epigenetic modifier mutations with class I and/or class II mutations for understanding the pathogenesis and novel therapeutic targets of AML. To understand the entire picture of molecular pathogenesis in AML, gene rearrangement, gene copy number, DNA methylation and expression profiles are needed to be analyzed with gene mutations. Furthermore, it is also important to validate which mutations should be included for the prognostic stratification system. Since newly identified mutations are recurrently, but infrequently identified in AML, very large-scale prospective studies are required to confirm their prognostic implications. Finally, it is expected that genome research promotes the development of new treatment.

Acknowledgments The data described in this manuscript contain unpublished data which are supported by the Project for Development of Innovative Research on Cancer Therapeutics, Ministry of Education, Culture, Sports, Science and Technology. We thank Prof. Seishi Ogawa (Tokyo University) and Prof. Hiroyuki Mano (Jichi Medical University) for helpful discussion.

\section{References}

1. Frohling S, Scholl C, Gilliland DG, Levine RL. Genetics of myeloid malignancies: pathogenetic and clinical implications. J Clin Oncol. 2005;23:6285-95.

2. Estey E, Dohner H. Acute myeloid leukaemia. Lancet. 2006;368: 1894-907.

3. Shima Y, Kitabayashi I. Deregulated transcription factors in leukemia. Int J Hematol. 2011;94:134-41.

4. Peterson LF, Zhang DE. The 8;21 translocation in leukemogenesis. Oncogene. 2004;23:4255-62.

5. Wang YY, Zhou GB, Yin T, Chen B, Shi JY, Liang WX, et al. AML1-ETO and C-KIT mutation/overexpression in $\mathrm{t}(8 ; 21)$ leukemia: implication in stepwise leukemogenesis and response to Gleevec. Proc Natl Acad Sci USA. 2005;102:1104-9.

6. Kelly LM, Kutok JL, Williams IR, Boulton CL, Amaral SM, Curley DP, et al. PML/RARalpha and FLT3-ITD induce an APLlike disease in a mouse model. Proc Natl Acad Sci USA. 2002;99: 8283-8.

7. Speck NA, Gilliland DG. Core-binding factors in haematopoiesis and leukaemia. Nat Rev Cancer. 2002;2:502-13.

8. Tang JL, Hou HA, Chen CY, Liu CY, Chou WC, Tseng MH, et al. AML1/RUNX1 mutations in 470 adult patients with de novo acute myeloid leukemia: prognostic implication and interaction with other gene alterations. Blood. 2009;114:5352-61. 
9. Wouters BJ, Lowenberg B, Erpelinck-Verschueren CA, van Putten WL, Valk PJ, Delwel R. Double CEBPA mutations, but not single CEBPA mutations, define a subgroup of acute myeloid leukemia with a distinctive gene expression profile that is uniquely associated with a favorable outcome. Blood. 2009;113:3088-91.

10. Koschmieder S, Halmos B, Levantini E, Tenen DG. Dysregulation of the C/EBPalpha differentiation pathway in human cancer. J Clin Oncol. 2009;27:619-28.

11. Marcucci G, Haferlach T, Dohner H. Molecular genetics of adult acute myeloid leukemia: prognostic and therapeutic implications. J Clin Oncol. 2011;29:475-86.

12. Radich JP, Kopecky KJ, Willman CL, Weick J, Head D, Appelbaum $\mathrm{F}$, et al. N-ras mutations in adult de novo acute myelogenous leukemia: prevalence and clinical significance. Blood. 1990;76:801-7.

13. Neubauer A, Dodge RK, George SL, Davey FR, Silver RT, Schiffer CA, et al. Prognostic importance of mutations in the ras proto-oncogenes in de novo acute myeloid leukemia. Blood. 1994;83:1603-11.

14. Nakao M, Yokota S, Iwai T, Kaneko H, Horiike S, Kashima K, et al. Internal tandem duplication of the flt 3 gene found in acute myeloid leukemia. Leukemia. 1996;10:1911-8.

15. Kiyoi H, Naoe T, Nakano Y, Yokota S, Minami S, Miyawaki S, et al. Prognostic implication of FLT3 and N-RAS gene mutations in acute myeloid leukemia. Blood. 1999;93:3074-80.

16. Yamamoto Y, Kiyoi H, Nakano Y, Suzuki R, Kodera Y, Miyawaki S, et al. Activating mutation of D835 within the activation loop of FLT3 in human hematologic malignancies. Blood. 2001;97:2434-9.

17. Paschka P. Core binding factor acute myeloid leukemia. Semin Oncol. 2008;35:410-7.

18. Beghini A, Peterlongo P, Ripamonti CB, Larizza L, Cairoli R, Morra E, et al. C-kit mutations in core binding factor leukemias. Blood. 2000;95:726-7.

19. Care RS, Valk PJ, Goodeve AC, Abu-Duhier FM, GeertsmaKleinekoort WM, Wilson GA, et al. Incidence and prognosis of c-KIT and FLT3 mutations in core binding factor (CBF) acute myeloid leukaemias. Br J Haematol. 2003;121:775-7.

20. Cairoli R, Beghini A, Grillo G, Nadali G, Elice F, Ripamonti CB, et al. Prognostic impact of c-KIT mutations in core binding factor leukemias: an Italian retrospective study. Blood. 2006;107: 3463-8.

21. Kelly LM, Liu Q, Kutok JL, Williams IR, Boulton CL, Gilliland DG. FLT3 internal tandem duplication mutations associated with human acute myeloid leukemias induce myeloproliferative disease in a murine bone marrow transplant model. Blood. 2002;99:310-8

22. Nakano Y, Kiyoi H, Miyawaki S, Asou N, Ohno R, Saito H, et al. Molecular evolution of acute myeloid leukaemia in relapse: unstable N-ras and FLT3 genes compared with p53 gene. Br J Haematol. 1999;104:659-64.

23. Bachas C, Schuurhuis GJ, Hollink IH, Kwidama ZJ, Goemans BF, Zwaan CM, et al. High-frequency type I/II mutational shifts between diagnosis and relapse are associated with outcome in pediatric AML: implications for personalized medicine. Blood. 2010;116:2752-8.

24. Cloos J, Goemans BF, Hess CJ, van Oostveen JW, Waisfisz Q, Corthals S, et al. Stability and prognostic influence of FLT3 mutations in paired initial and relapsed AML samples. Leukemia. 2006;20:1217-20.

25. Swerdlow S, Campo E, Harris N, Jaffe E, Pileri S, Stein H, et al. WHO classification of tumours of haematopoietic and lymphoid tissues. 4th ed. Lyon: WHO Press; 2008.

26. Falini B, Mecucci C, Tiacci E, Alcalay M, Rosati R, Pasqualucci $\mathrm{L}$, et al. Cytoplasmic nucleophosmin in acute myelogenous leukemia with a normal karyotype. N Engl J Med. 2005;352:254-66.
27. Suzuki T, Kiyoi H, Ozeki K, Tomita A, Yamaji S, Suzuki R, et al. Clinical characteristics and prognostic implications of NPM1 mutations in acute myeloid leukemia. Blood. 2005;106:2854-61.

28. Stirewalt DL, Radich JP. The role of FLT3 in haematopoietic malignancies. Nat Rev Cancer. 2003;3:650-65.

29. Kiyoi H, Naoe T. Biology, clinical relevance, and molecularly targeted therapy in acute leukemia with FLT3 mutation. Int $\mathbf{J}$ Hematol. 2006;83:301-8.

30. Kiyoi H, Naoe T. FLT3 in human hematologic malignancies. Leuk Lymphoma. 2002;43:1541-7.

31. Delhommeau F, Dupont S, Della Valle V, James C, Trannoy S, Masse A, et al. Mutation in TET2 in myeloid cancers. N Engl J Med. 2009;360:2289-301.

32. Langemeijer SM, Kuiper RP, Berends M, Knops R, Aslanyan MG, Massop M, et al. Acquired mutations in TET2 are common in myelodysplastic syndromes. Nat Genet. 2009;41:838-42.

33. Mardis ER, Ding L, Dooling DJ, Larson DE, McLellan MD, Chen K, et al. Recurring mutations found by sequencing an acute myeloid leukemia genome. N Engl J Med. 2009;361:1058-66.

34. Ley TJ, Ding L, Walter MJ, McLellan MD, Lamprecht T, Larson DE, et al. DNMT3A mutations in acute myeloid leukemia. N Engl J Med. 2010;363:2424-33.

35. Nikoloski G, Langemeijer SM, Kuiper RP, Knops R, Massop M, Tonnissen ER, et al. Somatic mutations of the histone methyltransferase gene EZH2 in myelodysplastic syndromes. Nat Genet. 2010;42:665-7.

36. Shih AH, Abdel-Wahab O, Patel JP, Levine RL. The role of mutations in epigenetic regulators in myeloid malignancies. Nat Rev Cancer. 2012;12:599-612.

37. Chou WC, Huang HH, Hou HA, Chen CY, Tang JL, Yao M, et al. Distinct clinical and biological features of de novo acute myeloid leukemia with additional sex comb-like 1 (ASXL1) mutations. Blood. 2010;116:4086-94.

38. Grossmann V, Tiacci E, Holmes AB, Kohlmann A, Martelli MP, Kern W, et al. Whole-exome sequencing identifies somatic mutations of BCOR in acute myeloid leukemia with normal karyotype. Blood. 2011;118:6153-63.

39. Li M, Collins R, Jiao Y, Ouillette P, Bixby D, Erba H, et al. Somatic mutations in the transcriptional corepressor gene BCORL1 in adult acute myelogenous leukemia. Blood. 2011; 118:5914-7.

40. Welch JS, Ley TJ, Link DC, Miller CA, Larson DE, Koboldt DC, et al. The origin and evolution of mutations in acute myeloid leukemia. Cell. 2012;150:264-78.

41. Ogawa S. Splicing factor mutations in myelodysplasia. Int $\mathbf{J}$ Hematol. 2012;96:438-42.

42. Visconte V, Rogers HJ, Singh J, Barnard J, Bupathi M, Traina F, et al. SF3B1 haploinsufficiency leads to formation of ring sideroblasts in myelodysplastic syndromes. Blood. 2012;120: 3173-86.

43. Guo JU, Su Y, Zhong C, Ming GL, Song H. Hydroxylation of 5-methylcytosine by TET1 promotes active DNA demethylation in the adult brain. Cell. 2011;145:423-34.

44. Tahiliani M, Koh KP, Shen Y, Pastor WA, Bandukwala $H$, Brudno Y, et al. Conversion of 5-methylcytosine to 5-hydroxymethylcytosine in mammalian DNA by MLL partner TET1. Science. 2009;324:930-5.

45. Ko M, Huang Y, Jankowska AM, Pape UJ, Tahiliani M, Bandukwala HS, et al. Impaired hydroxylation of 5-methylcytosine in myeloid cancers with mutant TET2. Nature. 2010;468:839-43.

46. Abdel-Wahab O, Mullally A, Hedvat C, Garcia-Manero G, Patel $\mathrm{J}$, Wadleigh M, et al. Genetic characterization of TET1, TET2, and TET3 alterations in myeloid malignancies. Blood. 2009;114: 144-7.

47. Metzeler KH, Maharry K, Radmacher MD, Mrozek K, Margeson $\mathrm{D}$, Becker H, et al. TET2 mutations improve the new European 
LeukemiaNet risk classification of acute myeloid leukemia: a Cancer and Leukemia Group B study. J Clin Oncol. 2011;29: 1373-81.

48. Gaidzik VI, Paschka P, Spath D, Habdank M, Kohne CH, Germing U, et al. TET2 mutations in acute myeloid leukemia (AML): results from a comprehensive genetic and clinical analysis of the AML study group. J Clin Oncol. 2012;30:1350-7.

49. Chou WC, Chou SC, Liu CY, Chen CY, Hou HA, Kuo YY, et al. TET2 mutation is an unfavorable prognostic factor in acute myeloid leukemia patients with intermediate-risk cytogenetics. Blood. 2011;118:3803-10.

50. Patel JP, Gonen M, Figueroa ME, Fernandez H, Sun Z, Racevskis $\mathrm{J}$, et al. Prognostic relevance of integrated genetic profiling in acute myeloid leukemia. N Engl J Med. 2012;366:1079-89.

51. He YF, Li BZ, Li Z, Liu P, Wang Y, Tang Q, et al. Tet-mediated formation of 5-carboxylcytosine and its excision by TDG in mammalian DNA. Science. 2011;333:1303-7.

52. Wu H, D'Alessio AC, Ito S, Wang Z, Cui K, Zhao K, et al. Genome-wide analysis of 5-hydroxymethylcytosine distribution reveals its dual function in transcriptional regulation in mouse embryonic stem cells. Genes Dev. 2011;25:679-84.

53. Ficz G, Branco MR, Seisenberger S, Santos F, Krueger F, Hore TA, et al. Dynamic regulation of 5-hydroxymethylcytosine in mouse ES cells and during differentiation. Nature. 2011;473: 398-402.

54. Moran-Crusio K, Reavie L, Shih A, Abdel-Wahab O, NdiayeLobry D, Lobry C, et al. Tet 2 loss leads to increased hematopoietic stem cell self-renewal and myeloid transformation. Cancer Cell. 2011;20:11-24.

55. Chedin F. The DNMT3 family of mammalian de novo DNA methyltransferases. Prog Mol Biol Transl Sci. 2011;101:255-85.

56. Thol F, Damm F, Ludeking A, Winschel C, Wagner K, Morgan $\mathrm{M}$, et al. Incidence and prognostic influence of DNMT3A mutations in acute myeloid leukemia. J Clin Oncol. 2011;29:2889-96.

57. Yan XJ, Xu J, Gu ZH, Pan CM, Lu G, Shen Y, et al. Exome sequencing identifies somatic mutations of DNA methyltransferase gene DNMT3A in acute monocytic leukemia. Nat Genet. 2011;43:309-15.

58. Fried I, Bodner C, Pichler MM, Lind K, Beham-Schmid C, Quehenberger F, et al. Frequency, onset and clinical impact of somatic DNMT3A mutations in therapy-related and secondary acute myeloid leukemia. Haematologica. 2012;97:246-50.

59. Ooi SK, Qiu C, Bernstein E, Li K, Jia D, Yang Z, et al. DNMT3L connects unmethylated lysine 4 of histone $\mathrm{H} 3$ to de novo methylation of DNA. Nature. 2007;448:714-7.

60. Tadokoro Y, Ema H, Okano M, Li E, Nakauchi H. De novo DNA methyltransferase is essential for self-renewal, but not for differentiation, in hematopoietic stem cells. J Exp Med. 2007;204:715-22.

61. Challen GA, Sun D, Jeong M, Luo M, Jelinek J, Berg JS, et al. Dnmt3a is essential for hematopoietic stem cell differentiation. Nat Genet. 2012;44:23-31.

62. Margueron R, Reinberg D. The Polycomb complex PRC2 and its mark in life. Nature. 2011;469:343-9.

63. Lessard J, Schumacher A, Thorsteinsdottir U, van Lohuizen M, Magnuson T, Sauvageau G. Functional antagonism of the Polycomb-Group genes eed and Bmil in hemopoietic cell proliferation. Genes Dev. 1999;13:2691-703.

64. Varambally S, Dhanasekaran SM, Zhou M, Barrette TR, KumarSinha C, Sanda MG, et al. The polycomb group protein EZH2 is involved in progression of prostate cancer. Nature. 2002;419: 624-9.

65. Morin RD, Johnson NA, Severson TM, Mungall AJ, An J, Goya $\mathrm{R}$, et al. Somatic mutations altering EZH2 (Tyr641) in follicular and diffuse large B-cell lymphomas of germinal-center origin. Nat Genet. 2010;42:181-5.
66. Tanaka S, Miyagi S, Sashida G, Chiba T, Yuan J, MochizukiKashio M, et al. Ezh2 augments leukemogenicity by reinforcing differentiation blockage in acute myeloid leukemia. Blood. 2012;120:1107-17.

67. Ernst T, Chase AJ, Score J, Hidalgo-Curtis CE, Bryant C, Jones $\mathrm{AV}$, et al. Inactivating mutations of the histone methyltransferase gene EZH2 in myeloid disorders. Nat Genet. 2010;42:722-6.

68. Abdel-Wahab O, Pardanani A, Patel J, Wadleigh M, Lasho T, Heguy A, et al. Concomitant analysis of EZH2 and ASXL1 mutations in myelofibrosis, chronic myelomonocytic leukemia and blast-phase myeloproliferative neoplasms. Leukemia. 2011; 25:1200-2.

69. Su IH, Basavaraj A, Krutchinsky AN, Hobert O, Ullrich A, Chait BT, et al. Ezh2 controls B cell development through histone H3 methylation and Igh rearrangement. Nat Immunol. 2003;4:124-31.

70. Dang L, Jin S, Su SM. IDH mutations in glioma and acute myeloid leukemia. Trends Mol Med. 2010;16:387-97.

71. Marcucci G, Maharry K, Wu YZ, Radmacher MD, Mrozek K, Margeson D, et al. IDH1 and IDH2 gene mutations identify novel molecular subsets within de novo cytogenetically normal acute myeloid leukemia: a Cancer and Leukemia Group B study. J Clin Oncol. 2010;28:2348-55.

72. Paschka P, Schlenk RF, Gaidzik VI, Habdank M, Kronke J, Bullinger L, et al. IDH1 and IDH2 mutations are frequent genetic alterations in acute myeloid leukemia and confer adverse prognosis in cytogenetically normal acute myeloid leukemia with NPM1 mutation without FLT3 internal tandem duplication. J Clin Oncol. 2010;28:3636-43.

73. Thol F, Damm F, Wagner K, Gohring G, Schlegelberger B, Hoelzer D, et al. Prognostic impact of IDH2 mutations in cytogenetically normal acute myeloid leukemia. Blood. 2010;116: 614-6.

74. Wagner K, Damm F, Gohring G, Gorlich K, Heuser M, Schafer I, et al. Impact of IDH1 R132 mutations and an IDH1 single nucleotide polymorphism in cytogenetically normal acute myeloid leukemia: SNP rs11554137 is an adverse prognostic factor. J Clin Oncol. 2010;28:2356-64.

75. Ward PS, Patel J, Wise DR, Abdel-Wahab O, Bennett BD, Coller HA, et al. The common feature of leukemia-associated IDH1 and IDH2 mutations is a neomorphic enzyme activity converting alpha-ketoglutarate to 2-hydroxyglutarate. Cancer Cell. 2010;17: 225-34.

76. Dang L, White DW, Gross S, Bennett BD, Bittinger MA, Driggers EM, et al. Cancer-associated IDH1 mutations produce 2-hydroxyglutarate. Nature. 2009;462:739-44.

77. Zhao S, Lin Y, Xu W, Jiang W, Zha Z, Wang P, et al. Gliomaderived mutations in IDH1 dominantly inhibit IDH1 catalytic activity and induce HIF-1alpha. Science. 2009;324:261-5.

78. Carretero M, Remeseiro S, Losada A. Cohesin ties up the genome. Curr Opin Cell Biol. 2010;22:781-7.

79. Millau JF, Gaudreau L. CTCF, cohesin, and histone variants: connecting the genome. Biochem Cell Biol. 2011;89:505-13.

80. Dolnik A, Engelmann JC, Scharfenberger-Schmeer M, Mauch J, Kelkenberg-Schade S, Haldemann B, et al. Commonly altered genomic regions in acute myeloid leukemia are enriched for somatic mutations involved in chromatin-remodeling and splicing. Blood. 2012;120:e83-e92.

81. Walter MJ, Shen D, Ding L, Shao J, Koboldt DC, Chen K, et al. Clonal architecture of secondary acute myeloid leukemia. N Engl J Med. 2012;366:1090-8.

82. Pagan JK, Arnold J, Hanchard KJ, Kumar R, Bruno T, Jones MJ, et al. A novel corepressor, BCoR-L1, represses transcription through an interaction with CtBP. J Biol Chem. 2007;282: $15248-57$.

83. Fisher CL, Pineault N, Brookes C, Helgason CD, Ohta H, Bodner $\mathrm{C}$, et al. Loss-of-function Additional sex combs like 1 mutations 
disrupt hematopoiesis but do not cause severe myelodysplasia or leukemia. Blood. 2010;115:38-46.

84. Sinclair DA, Milne TA, Hodgson JW, Shellard J, Salinas CA, Kyba M, et al. The Additional sex combs gene of Drosophila encodes a chromatin protein that binds to shared and unique Polycomb group sites on polytene chromosomes. Development. 1998;125:1207-16.

85. Abdel-Wahab O, Adli M, Lafave LM, Gao J, Hricik T, Shih AH, et al. ASXL1 mutations promote myeloid transformation through loss of PRC2-mediated gene repression. Cancer Cell. 2012;22: 180-93.

86. Bejar R, Stevenson K, Abdel-Wahab O, Galili N, Nilsson B, Garcia-Manero $\mathrm{G}$, et al. Clinical effect of point mutations in myelodysplastic syndromes. N Engl J Med. 2011;364:2496-506.

87. Metzeler KH, Becker H, Maharry K, Radmacher MD, Kohlschmidt J, Mrozek K, et al. ASXL1 mutations identify a high-risk subgroup of older patients with primary cytogenetically normal AML within the ELN favorable genetic category. Blood. 2011; 118:6920-9.

88. Grossmann V, Schnittger S, Kohlmann A, Eder C, Roller A, Dicker F, et al. A novel hierarchical prognostic model of AML solely based on molecular mutations. Blood. 2012;120:2963-72.

89. Stein BL, Williams DM, O'Keefe C, Rogers O, Ingersoll RG, Spivak JL, et al. Disruption of the ASXL1 gene is frequent in primary, post-essential thrombocytosis and post-polycythemia vera myelofibrosis, but not essential thrombocytosis or polycythemia vera: analysis of molecular genetics and clinical phenotypes. Haematologica. 2011;96:1462-9.
90. Damm F, Kosmider O, Gelsi-Boyer V, Renneville A, Carbuccia $\mathrm{N}$, Hidalgo-Curtis $\mathrm{C}$, et al. Mutations affecting mRNA splicing define distinct clinical phenotypes and correlate with patient outcome in myelodysplastic syndromes. Blood. 2012;119:3211-8.

91. Gelsi-Boyer V, Brecqueville M, Devillier R, Murati A, Mozziconacci MJ, Birnbaum D. Mutations in ASXL1 are associated with poor prognosis across the spectrum of malignant myeloid diseases. J Hematol Oncol. 2012;5:12.

92. Bachas C, Schuurhuis GJ, Assaraf YG, Kwidama ZJ, Kelder A, Wouters $\mathrm{F}$, et al. The role of minor subpopulations within the leukemic blast compartment of AML patients at initial diagnosis in the development of relapse. Leukemia. 2012;26:1313-20.

93. Ding L, Ley TJ, Larson DE, Miller CA, Koboldt DC, Welch JS, et al. Clonal evolution in relapsed acute myeloid leukaemia revealed by whole-genome sequencing. Nature. 2012;481:506-10.

94. Grimwade D, Hills RK, Moorman AV, Walker H, Chatters S, Goldstone AH, et al. Refinement of cytogenetic classification in acute myeloid leukemia: determination of prognostic significance of rare recurring chromosomal abnormalities among 5876 younger adult patients treated in the United Kingdom Medical Research Council trials. Blood. 2010;116:354-65.

95. Dohner H, Estey EH, Amadori S, Appelbaum FR, Buchner T, Burnett AK, et al. Diagnosis and management of acute myeloid leukemia in adults: recommendations from an international expert panel, on behalf of the European LeukemiaNet. Blood. 2010;115:453-74. 